\title{
International Survey of Clinical Engineering Professionals
}

\section{By Y. David ', S. Calil'², N. Pallikarakis ${ }^{3}$, M. Poluta ${ }^{4}$, K. Stavrianou ${ }^{5}$, S. Bergamasco ${ }^{6}$, D. Clark ${ }^{7}$, T. Judd ${ }^{8}$, J. Wear ${ }^{9}$, T. Easty ${ }^{10}$}

${ }^{1}$ Global Clinical Engineering Summit Chairman, USA

${ }^{2}$ Clinical Engineering Professor, Brazil

${ }^{3}$ Chairman of the Institute of Biomedical Technology, Greece

${ }^{4}$ Clinical Engineer, South Africa

${ }^{5}$ IFMBE/Clinical Engineering Division Secretariat, UK

${ }^{6}$ Italian Clinical Engineers Association (AIIC), Italy

${ }^{7}$ Clinical Engineering, Nottingham University Hospitals NHS Trust, UK

${ }^{8}$ IFMBE/Clinical Engineering Division Chairman, USA

${ }^{9}$ Clinical Engineering Consultant, USA

${ }^{10}$ Clinical Engineering Professor, Canada

\begin{abstract}
To determine the maturity of a profession one must have knowledge of the individual attributes of the practitioners of that profession and the universal strength of unique skills among them. We have conducted an international survey of Clinical Engineering (CE) professionals associated with the management of technological tools developed for and deployed within the healthcare delivery system. The survey targeted participants who are practicing engineering tasks related to the safe and efficient management of technology used in the delivery of healthcare services. The participants, consisted of cohort of individuals whose contact information was collected from attendees at previous clinical and biomedical engineering events including: (1) presentation at congresses/regional meetings, (2) serving on international technical committees or task forces, (3) attending virtual clinical engineering events, or (4) subscribing to the Global Clinical Engineering Journal. The purpose of the survey was to identify the state of organization of CE professionals and the potential gaps, if any exists, in meeting their professional development needs. The survey was developed and conducted using on-line internet apps and links that provided access to a questionnaire in six different languages to facilitate optimal participation and response accuracy in as many geographical regions as possible. The survey was conducted in the early part of 2020 over period of 6 weeks. The overall response rate ${ }^{1}$ was over $5 \%$ (total of 14,400 individual contacts less estimated 1,750 contacts who did not open/bounced back). A total of 667 responses from 89 countries were received. This survey is considered an improvement, over previously reported international surveys, ${ }^{2,3}$ with regard to response volume and rate. The strength of this survey, having larger response volume and geographical representation, when compared with previously documented CE surveys has improved even with narrower time window of data collection. The current survey consisted of twelve questions, beginning with information request about the respondent professional affiliation and moves on to request the ranking of the criticality of C.E. specific issues, while another question provided for comments in free formatting text style. The responses received were in all of the seven languages posted and included representation from all the continents. The analysis of the survey responses shows that about $60 \%$ of the responders identified themselves as clinical engineers, $16 \%$ as other type of engineers, $13 \%$ as technicians, and $12 \%$ as health professionals. Responses to particular questions demonstrate highest ratio of number of affirmative to negative responses. They were related to the perceived value responders placed on stronger international collaboration and on their willingness to engage in it. A conclusion, based on the analysis of the responses to this international survey, that the CE profession is awaiting the consolidation of the momentum generated by growing healthcare needs and present global conditions. The identified gap is lack of a dedicated international representation that is clearly identifiable within the CE field. Analysis of the survey data suggests the need of an international framework focusing on the various CE professional groups/associations and their members to face present challenges. The establishment of a global alliance to clearly identify the field of clinical engineering; to promote public awareness; to form liaison with government agencies and other healthcare decision makers, will improve global cooperation and inter CE societal relations that will serve patients as well.
\end{abstract}

Keywords - Clinical engineering, survey, questionnaire, global, association, professional, technicians, health, international, alliance, collaboration.

Copyright (C) 2021. This is an open-access article distributed under the terms of the Creative Commons Attribution License (CC BY): Creative Commons - Attribution 4.0 International - CC BY 4.0. The use, distribution or reproduction in other forums is permitted, provided the original author(s) and the copyright owner(s) are credited and that the original publication in this journal is cited, in accordance with accepted academic practice. No use, distribution or reproduction is permitted which does not comply with these terms. 


\section{INTRODUCTION}

The dependency of healthcare systems on technology for the delivery of their services is at an all-time high and projected to continuously grow. ${ }^{4,5}$ In addition, costs associated with the provisioning of healthcare programs are showing an increasing trend to consuming a large portion of total national gross product. ${ }^{6}$ To maximize patient care outcomes and to achieve optimal return on the investment in healthcare technology, it is important to manage the healthcare technology life cycle. This is the main area that clinical engineers, and related technologists and technicians are trained to apply their respective competencies to cost effectively manage and service healthcare technology.

To meet the need to determine how well optimal management of healthcare technology is improving the ability of care providers to practice their profession, undamental data must be collected relating to how well the needs of the professionals who manage and service this industry are being met. ${ }^{7}$ The authors intended to gain new knowledge about the needs of CE practitioners. Specifically, how to overcome lack of opportunities for sustaining sharing of knowledge between international clinical engineering practitioners due to limited clinical engineering professional associations knowledge sharing and exchanging.

Other researchers attempted, in previous work, to determine availability and the extent of CEs responsibilities were deployed by using survey methodology and concluded that lack of harmonization and wide variation are evident in the management of hospitals biomedical technology around the world. ${ }^{8}$ Reported results of one of the early surveys looked at CE effectiveness at hospitals in developing countries included 163 responses from 43 countries mostly from Africa, Latin America and Asia."

This survey states "This is the first study to collect and analyze data on the complexity and state of hospital equipment across the developing world; additionally, it is the first to collect significant responses from Africa. Prior to this study, only 10 developing countries had been profiled in international studies." To increase knowledge of a field of practice and to identify attributes of practitioners in that field can be accomplished through a survey. However, limited response volume and the only few published surveys recorded in the international CE field highlight the challenge that this work is addressing in an attempt to gain understanding of current state of the CE profession needs.

A survey that directly seeks answers from the involved community according to industry norms suggests that "Wherever possible, researchers should use existing data, and not bother people again with questions they have already answered in other surveys or can be found in registers." ${ }^{10}$ The International Handbook of Survey Methodology ${ }^{7}$ identifies a survey as "A study that collects planned information from a sample of individuals in order to estimate particular population characteristics. It further concludes that "Although sample surveys are costly and time-consuming, it may turn out that they are in many situations simply the best instrument for collecting high quality, relevant data" we designed the optima survey format to be by short content without open ended style, and yet providing fo free text format area at the end of the survey to collect additional information not included within the forma set of questions.

\section{METHODOLOGY}

One specific form of data collection method was an online survey consisting of a set of structured questions that can be clearly understood by the expected respondents. The online survey delivers advantages of being easy to respond to and efficient to analyze, having a low margin of errors as respondents select buttons and can easily change or correct their choices prior to submission. Available on-line tools can be used to analyze the data in variety of determinants. In addition, the survey was offered online with applications that could be easily be read and responded to on a working station, tablet, as well as other mobile devices.

Most surveys have a goal of being able to make inferences about points of interest in the target population. In general, one is faced with the need to make assumption that the persons in the data collection sample are simila on the characteristics of interest to persons not in the sample to be able to make inferences about the population. As such, the design of a survey is critical to its success, and therefore special attention should be given to fit the survey design and structure the questions to clearly
The optimal survey format to be used is based on literature of systematic survey and analysis of the use of international population surveying methods in various other fields. Our survey used a questionnaire template style following an introductory statement about its purpose and identifying its administrators and timetable for response acceptance. Clear and simple questions' pose and iddifying its admist language, together with a small number of questions and the use of multiple-choice questions style were all intended to help increase survey response rate. ${ }^{11}$ Since the total size of the international community of practicing C.E. is unknown at present and the response rate of previous survey was $\operatorname{low}^{9}$ the sampling methods for this research study was probability sampling ${ }^{12}$ where members of the community are chosen randomly. The survey questions were translated into six different languages, in addition to English, to facilitate better response rate from the different continents and countries. The languages used included: English, Spanish, French, Arabic, Chinese, French, and Russian.

A short introductory that preceded the questionnaire explained for the community who received it the survey's purpose and the importance of completing the questionnaire. It is presented in figure 1 below.

\section{coon

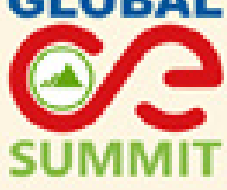

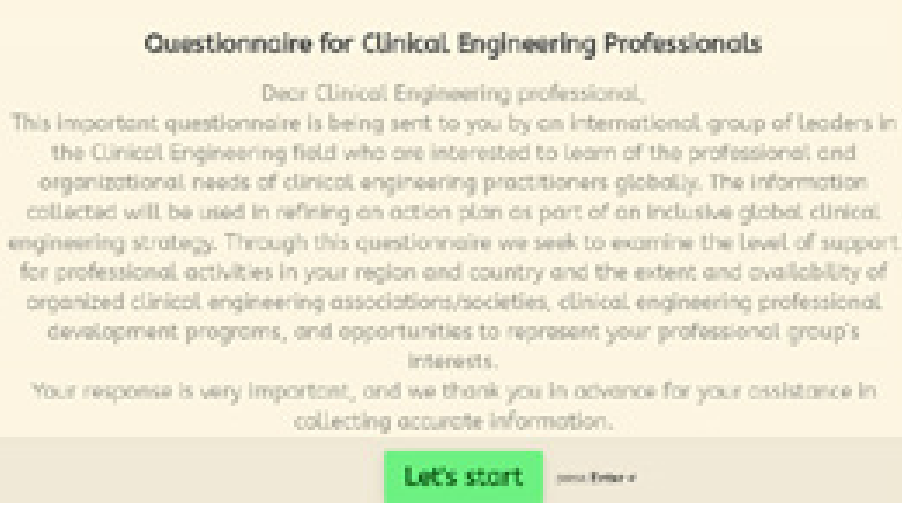

FIGURE 1. Introduction explaining the purpose of the Questionnaire.
The questionnaire consisted of twelve questions, eight of them (shown in table 1 below) having multiple choice answers, three asking for additional information and one provides space for free text format at the end of the questionnaire to collect un-prescribed comments. The last question ask the responders for ranking of profession cliter The The main questions are shown in the following table thew and the full question found in the appendix.

\section{TABLE 1. Questionnaire format}

Question

Response

Engineer - A Clinical/biomedical

Engineer

Engineer (other)

Are you a member of one of the Clinical Engineering Technician

following professional group (BME $)$

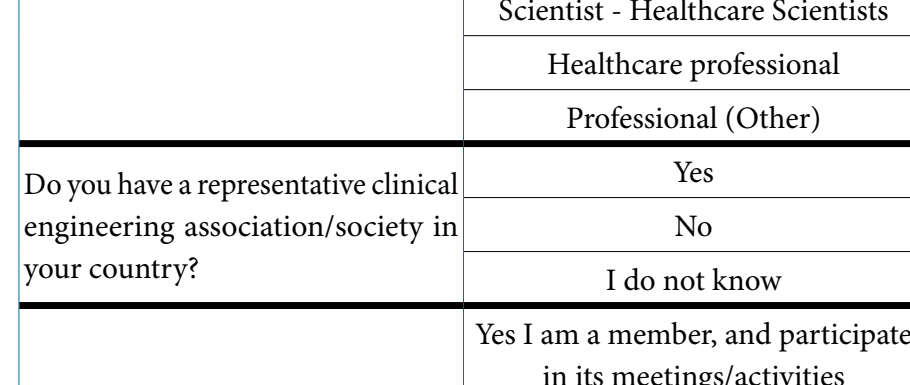

Yes I am a member, and part

Yes I am a member, but do not

Are you a member of the Association/
Society and do you participate in $\mathrm{I}$ am a member, but do not
participate in its meetings/activities \begin{tabular}{l|l|l|l}
$\begin{array}{l}\text { Society and do you participate in } \\
\text { their meetings or programs? }\end{array}$ & Not yet, but plan to do so in the
\end{tabular}

\begin{tabular}{|c|c|}
\cline { 2 - 2 } & No \\
\hline $\begin{array}{l}\text { Are there any higher education-based } \\
\text { programs in the area of clinical }\end{array}$ & Yes \\
\hline engineering offered in your country? & I do not know \\
\hline $\begin{array}{l}\text { Would you volunteer a few hours } \\
\text { a month to help advance clinical } \\
\text { engineering and its application and } \\
\text { impact locally and globally? }\end{array}$ & Yes \\
\hline $\begin{array}{l}\text { Do you see value in an international } \\
\text { organization focusing the needs of } \\
\text { clinical engineering? }\end{array}$ & I am not sure \\
\hline
\end{tabular}

clinical engineering? 


TABLE 1. Questionnaire format (continue)
\begin{tabular}{|c|c|}
\hline Question & Response \\
\hline \multirow{3}{*}{$\begin{array}{l}\text { Would you participate in the activities } \\
\text { of such an organization? }\end{array}$} & Yes \\
\cline { 2 - 2 } & I am not sure \\
\hline \multirow{4}{*}{$\begin{array}{l}\text { What are the top challenges we should } \\
\text { address? (you can add your own at } \\
\text { the end of the list) }\end{array}$} & Education-Training \\
\cline { 2 - 2 } & Recognition \\
\cline { 2 - 2 } & Engagement with leaders \\
\cline { 2 - 2 } & Career progression \\
\cline { 2 - 2 } & Publication opportunity \\
\cline { 2 - 2 } & other \\
\hline
\end{tabular}

\section{RESULTS}

The volume of responses to the survey that were collected over relatively short time (six weeks) suggests that the survey was clear to understand and that subject matter was of interest to responders. As a matter of fact, the average time to complete the survey was measured to be 11:27 minutes for desktops, over 3 minutes for tablets, and over 8 minutes for mobile devices all respectfully for users of the English language. It is also interesting that although the number of responses from English speaking countries like USA, UK, Ireland, Canada, and Australia accounted for 121 participants, the number of survey responses in the English language was 282; suggesting that individuals found the survey questions to be sufficiently clear even as a second language.

Responses were received from all the continents and are shown in figure 2 below. The blue color indicates location from where responses were received, and the color intensity indicates volume of responses with darker blue means larger volume.

The first question was about the professional standing of the respondent. Of the total of 669 responses received: $59 \%$ of the respondents identified themselves as clinical or biomedical enginer, $16 \%$ identified themselves as or bives as other type of engineer, $13 \%$ identified themselves as clinical engineering technician, healthcare scientists were checked at $5 \%$, healthcare professional at $4 \%$, and other
professional were marked $3 \%$. A graphical presentation

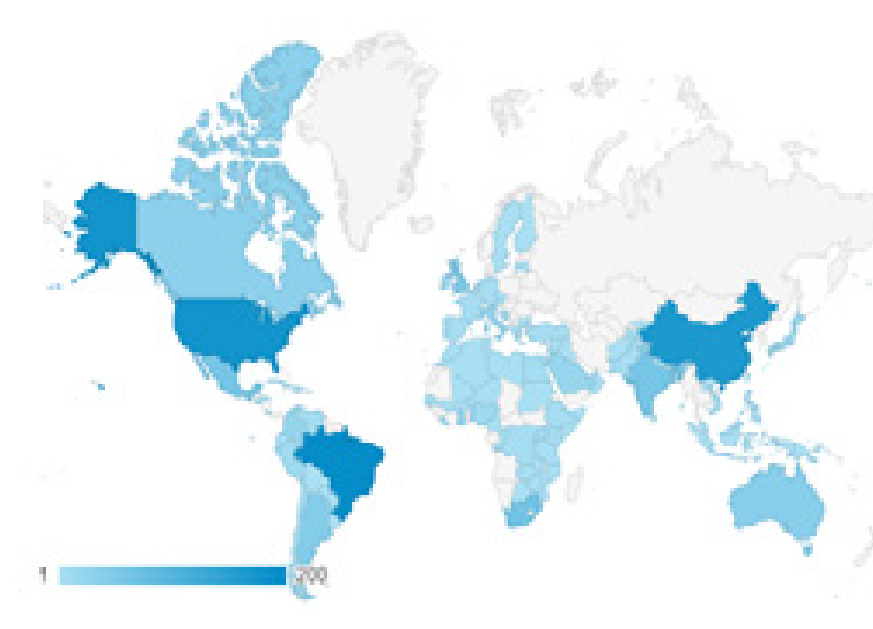

FIGURE 2. World map showing in levels of color intensity origin of the responses received.

TABLE 2. Questionnaire participation by continent

\begin{tabular}{|l|c|}
\hline \multicolumn{1}{|c|}{ Continent } & Participation \\
\hline Australia & 23 \\
\hline $\begin{array}{l}\text { Africa (Rwanda, Nigeria, Ghana, Ethiopia, } \\
\text { Uganda, Egypt, Kenya, Bhutan, Zambia, } \\
\text { Somalia, Zimbabwe, South Africa, Senegal, } \\
\text { Benin, Cameroon, Niger, Tanzania, Botswana) }\end{array}$ & 76 \\
\hline $\begin{array}{l}\text { North America (USA, Canada, Mexico, El } \\
\text { Salvador, Costa Rica) }\end{array}$ & 101 \\
\hline $\begin{array}{l}\text { South America (Brazil, Peru, Colombia, } \\
\text { Venezuela, Argentina, Ecuador, Bolivia, Chile, } \\
\text { Cuba, Puerto Rico, Uruguay) }\end{array}$ & 200 \\
\hline $\begin{array}{l}\text { Asia (China, India, Lebanon, Bangladesh, } \\
\text { Bhutan, Bahrain, Japan, Jordan, Nepal, Pakistan, } \\
\text { Philippines, Qatar, Saudi Arabia, Singapore, } \\
\text { Turkey, United Arab Emirates, Yemen, Syria) }\end{array}$ & \multicolumn{1}{|c|}{142} \\
\hline $\begin{array}{l}\text { Europe (Italy, France, UK, Ireland, Spain, } \\
\text { Portugal, Greece, Germany, Latvia, Netherlands, } \\
\text { Sweden, Bosnia and Herzegovina, Czech } \\
\text { Republic, Russia) }\end{array}$ & \multicolumn{1}{|c|}{86} \\
\hline
\end{tabular}

of the results of question number \# 1 is shown in Figure 3 below.

The second question addressed information about the prevalence of CE national societies, where $73 \%$ answered that they have such an association or society, $20 \%$ did not, and $7 \%$ were not sure.

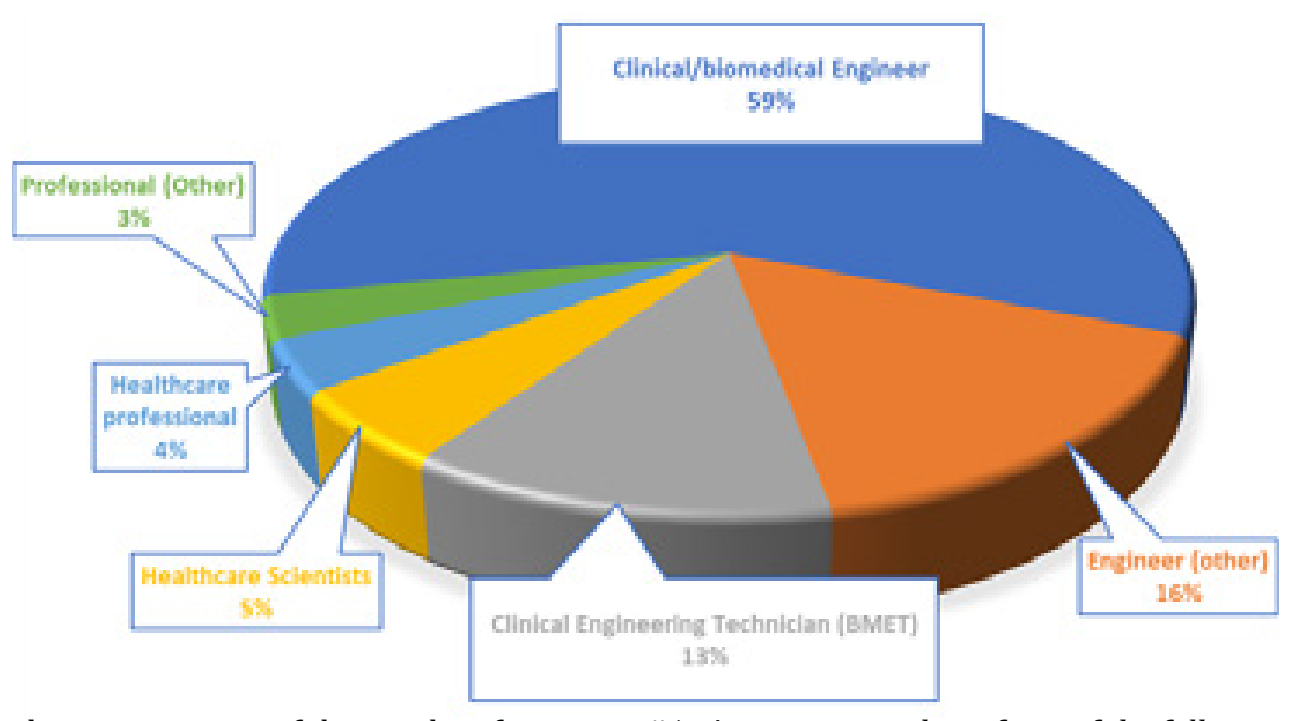

FIGURE 3. Graphical representation of the results of question \#1: Are you a member of one of the following professional groups?

The fourth question asked if the respondent is a member of such an organization and do you participate in its meeting or activities; $48 \%$ responded that yes, they are members and participate. While $17 \%$ wrote that they are members but do not participate, while $20 \%$ said that they are not but planned to join in the future, and $15 \%$ replied with No, as shown in figure 4 below.

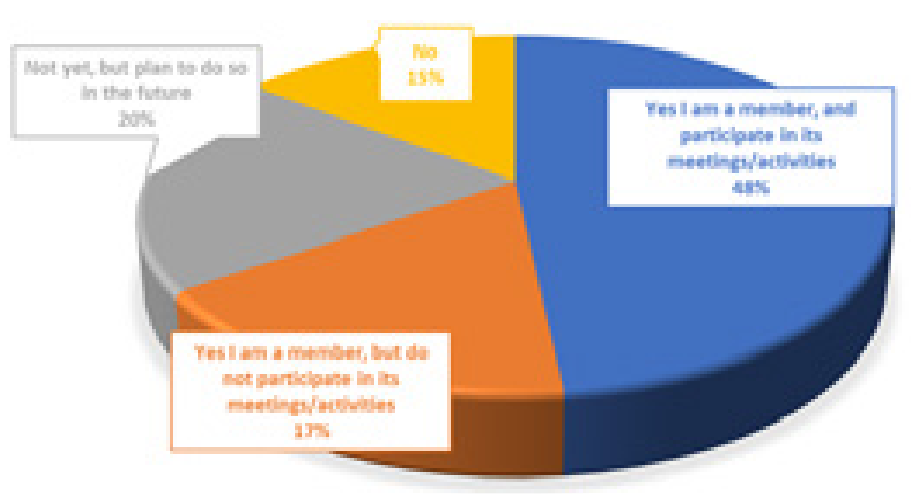

FIGURE 4. Graphical representation of the results of question $\# 4$ : Are you a member of the Association/Society and do you participate in their meetings or programs?

The fifth question asked about higher education-based programs being offered in the field of CE in your country? pros Respese sixth question asked: Would you volunteer a few hours a month to help advance clinical engineering and its application and impact locally and globally? the answers show distribution of $86 \%$ Yes, $4 \%$ No, and $10 \%$ Not sure. The two questions that received the highest ratio of positive to negative responses were question number 7 and question 8, shown in table 3 below. Question number 7: Do you see value in an international organization focusing the needs of clinical engineering? This question registered the highest positive responses with $93 \%$ Yes, $2 \%$ No, and 5\% Not sure. Question seven is important for the understanding of the responders' level of perceived value and need for global organization to unite the $\mathrm{CE}$ field. To the question . ies of such an , with $\mathrm{No}$, and $12 \%$ were not sure.

TABLE 3. Responses to survey questions \# 7 \& \#8

\begin{tabular}{|l|c|c|c|}
\hline \multicolumn{1}{|c|}{ Question } & \multicolumn{3}{|c|}{ Response } \\
\hline \multirow{2}{*}{$\begin{array}{l}\text { Do you see value in an international } \\
\text { organization focusing the needs of } \\
\text { clinical engineering? }\end{array}$} & Yes & 612 & $93 \%$ \\
\cline { 2 - 4 } & I am not sure & 13 & 22 \\
\hline \multirow{2}{*}{$\begin{array}{l}\text { Would you participate in the activities } \\
\text { of such an organization? }\end{array}$} & Yes & 553 & $84 \%$ \\
\cline { 2 - 4 } & I am not sure & 76 & $12 \%$ \\
\hline
\end{tabular}

Next, responders were asked to rank in order of importance eight topics, shown in table below. These topics were discused at shown in table below. These show continuous growing attendance over the last five years as during the 2019 Third International CE and HTM 
Congress, Rome, Italy, having record number of accepted abstracts and of international participation. ${ }^{14}$ The top challenges that needed to be addressed were listed. The analysis of the survey results shows the following order for the challenges as were ranked by responders:

TABLE 4. Questionnaire results show order ranking of top challenges in current CE field

\begin{tabular}{|c|c|}
\hline Challenges in CE field & Answers \\
\hline Education-Training & 446 \\
\hline Recognition & 361 \\
\hline Professional Standing-Credentialing & 337 \\
\hline Engagement with leaders & 270 \\
\hline Networking & 230 \\
\hline Career progression & 299 \\
\hline Publication opportunity & 184 \\
\hline other & 31 \\
\hline
\end{tabular}

\section{DISCUSSION AND CONCLUSIONS}

Most of previously reported surveys conducted in the clinical engineering field resulted in relatively small response volume and rate. These surveys were discussed in the introduction segment of this manuscript. The present survey was distributed and available for response for shorter time duration than the previous surveys and yet the volume of the responses was higher. The results of this clinical engineering international survey provide representative data that suggest gaps in building sustainable global exchange of knowledge and profession tex networking between groups/associations of clinical

The survey essentially composes of two parts. The multiple-choice questionnaire (part I) and the ranking of challenges and free text (part II). The results from part I, deem to suggest that a positive change taking place in the CE field reflected by growth in the volume of the number of national CE associations around the world as reflected by the relatively high confirmation response rate to question two "do you have CE association in your cour (73\%) and to guestion four about participation (7) for for same phenomenon observed by the data, is the high positive response to the question about availability of higher education-based program in your area (74\%).

However, this stands in contrast to the results analyzed for part II - the ranking of the top challenges the responders are facing. The data clearly reveals that the most important challenges responders face are limited availability of education and training (446 responses) follow by lack of professional recognition (361 responses) and by absence of professional credentialing program (337 responses). All other listed challenges recorded less than 200 responses each, placing higher significan on the top three.

The data also sufficiently demonstrate a clear and overwhelming positive response for the value seen in havoverwhelnin (612 resonses) as wll as for respords' (612 responses) as well as for responders' intention to participate in such an organization (553 responses). It is also revealing to see that only $2 \%$ of the responders (13 responses) do not perceive of such a value. The combination of the results of (part I ) of this questionnaire with the ranking of top challenges the CE field is facing (pat II), with also the growing attendance at international CE congresses, and the recent increase volume of CE publications ${ }^{15}$ - reveals a CE field in the midst of a professional evolution in need of leadership to further facilitate its important impact on healthare programs. The survey highlighted the state ofCE associations, networkingey highlght fessional challenges, and the desire for more international cooperation that leads needed professional development programs. Programs that support expansion of skills, job responsibilities and equal participation in healthcar teams. Patient care outcomes stand to improve when healthcare technology is optimally managed. Identifying the global challenges faced by international community of CEs is the first step towards overcoming them and the shared goal of better healthcare outcomes can then be better guided. Establishment of global collaboration and structure to achieve partnerships will help to overcome barriers, support professional development and income

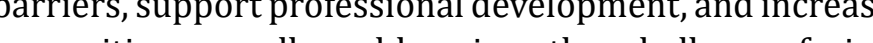
the CE profession.

Based on the analysis of the survey data, one such initiative can be to unify the global CE field and provide framework for the various professional groups/associations and their members with continuous opportunity for collaborations across areas and on issues better resolved on an international level. As such, the establishment of a global structure clearly identifying unified field of clinical engineering that will: promote public awareness; form liaison with government agencies and other healthcare decision makers; and improveies and other healthcare decision makers, and improve international cooperation and inter societies relations and will ultimately support better patients care and wellness everywhere.

\section{ACKNOWLEDGEMENTS}

The authors would like to thank all of the translators who helped convert the questionnaire from English into additional total of six languages. German Giles (Spanish), Saide Calil (Portuguese), Farid Riad (Arabic), Zheng Kun Saide Calil (Portuguese), Farid Riad (Arabic), Zheng Kun
(Chinese), Andrei Issakov (Russian), Nicolas Pallikarakis (French).

\section{REFERENCES}

1. M. Clark, M. Rogers, A. Foster, F. Dvorchak, F. Saadeh, J. Weaver, V. Mor: A Randomized Trial of the Impact of Survey Design Characteristics on Response Rates Among Nursing Home Providers Eval Health Prof. 2011;34(4):464-486. doi:10.1177/0163278710397791.

2. L. Nascimento, S. Calil, T. Judd, Y. David: Analysis of IFMBE-CED 2017 Worldwide Clinical Engineering Survey, Global Clinical Engineering Journal, Vol. 2,
Issue 1, December 2019 https://doi.org/10.31354/ Issue 1, December
globalce.v2i1.70

3. M. Frize, X. Cao, I. Roy: Survey of Clinical Engineering in Developing Countries and Model for Technology Acquisition and Diffusion, Proceedings of IEEE, 2005 EMBS $27^{\text {th }}$ annual conference, Shanghai, China, Sept. 1-4, 2005. https://ieeexplore.ieee.org/abstract/ 1-4, 2005. https://
document/1616369

4. J. Dyro: Clinical Engineering: Evolution of a Discipline, Clinical Engineering Handbook, Chapter 1, Elsevier Academic Press Series in Biomedical Engineering, USA, 2004

5. Clinical Engineering Handbook, E. Iadanza (ed.), Chapter 1, Second Edition, Academic Press, Elsevier 2020. https://www.elsevier.com/books/ clinical-engineering-handbook/iadanza/978-0 12-813467-2? countrycode=US\&format=print \& utm_source=google_ads\&utm_medium=paid_search\&utm campaign=usashopping\&gclid=CjwKCAjw4rf6BRAvEiwAn2Q76u0EU1BXj0Asb7pYRSpRovmzQWMPIJH6BFXJq2k9B1xkm0RLqmbYgxoCeiYQAvD_BwE

6. American Institute for Medical and Biological Engineering, Wiley Encyclopedia of Biomedical Engineering, April 2006. https://www.wiley.com/en-us/Wiley+E ncyclopedia + of + Biomedical+Engineering $\% 2 C+6+V$ olume+Set-p-9780471249672

7. de Leeuw, E. D., Hox, J. J., \& Dillman, D. A. (Eds.). International handbook of survey methodology. Taylor $\&$ Francis Group/Lawrence Erlbaum Associates. (2008). https://psycnet.apa.org/record/2008-04187-000

8. M. Glouhova, N. Pallikarakis: World Clinical Engineering Survey, Clinical Engineering Handbook, Chapter 15, Elsevier Academic Press Series in Biomedical Engineering, USA, 2004.

9. S. Mullaly, M. Frize: Survey of clinical engineering effectiveness in developing world hospitals: equipment resources, procurement and donations, Conference Proceedings IEEE/EMBS 2008, doi: 10.1109/ IEMBS.2008.4650212.

10.D. Korniewicz, T. Clark, Y. David: A National Online Survey on the Effectiveness of Clinical Alarms, American Journal of Critical Care 17 (1):36-41, January 2008. https://aacnjournals.org/ajcconline/articleabstract/17/1/36/643/A-National-Online-Survey-onthe-Effectiveness-of?redirectedFrom=fulltext

11. Part IV Culture, Cognition and Response in Survey Methods in Multinational, Multiregional, and Multicultural Contexts, edited by Harkness et al. 2010, John Wiley \& Sons, Inc. https://www.researchgate.net/profile/ Daphna_Oyserman/publication/230015384_Cognition Communication_and_Culture_Implications_for_the_Survey Response_Process/links/59eccf864585151983ccd415/ Cognition-Communication-and-Culture-Implicationsfor-the-Survey-Response-Process.pdf

12.B. Schouten, F. Cobben, J. Bethlehem: Indicators for the representativeness of survey response, Survey Methodology, June 2009, Vol. 35, No. 1, pp. 101-113 Canada https://www.researchgate.net/profile/ Jelke_Bethlehem/publication/267836796_Indicators_for_the_Representativeness_of_Survey_Response/ 
links/547458fc0cf245eb436dd8ae/Indicators-for-theRepresentativeness-of-Survey-Response.pdf

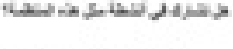

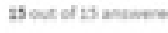
Congress, Rome, Italy, 2019. https://ced.ifmbe.org/ blog/ifmbe-ced-cestatus-cesummit2019.htm

14.International Clinical Engineering and Health Technology Management Congress, Rome, Italy, October 21-22 2019. http://wwwicehtmc2019.com/papersubmission.html

15. Making a Difference - Global Health Technology Success Stories: Overview of over 400 submissions from 125 Countries. Global Journal of Clinical Engineering, Vol.1, No. 1, 2018. https://www.globalce.org/index. php/GlobalCE/article/view/43

\section{APPENDIX I}

The following question was selected as an example for the use of multilanguage translation (English, Portuguese, Arabic, Chinese, French, Russian and Spanish) and are shown in their original posting in the figures below.

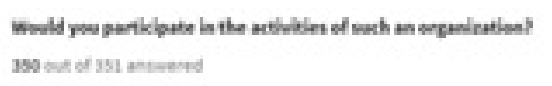

notwe

no

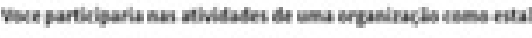

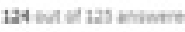

$\sin$

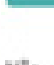

Nas

Nbo ommo certere

$\square$
$1-$

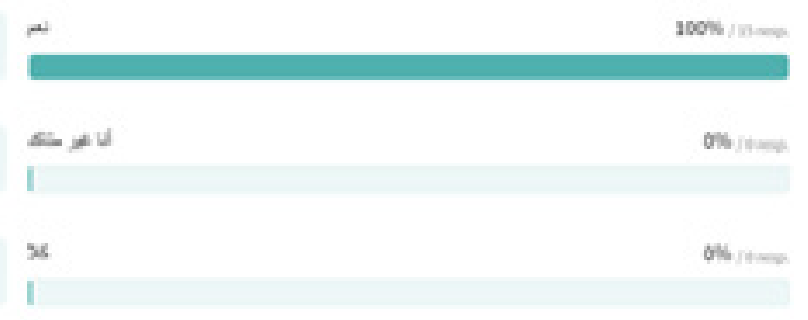

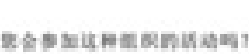

nomeln esiment
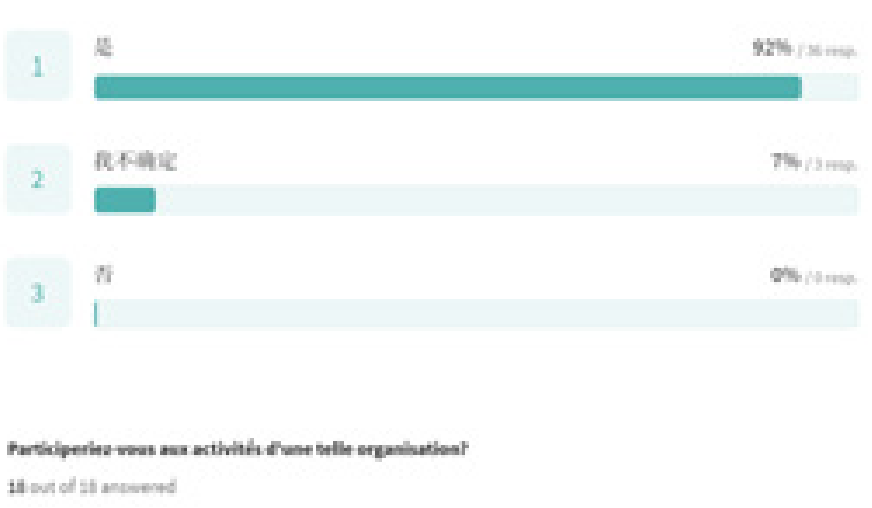

\section{oil}

som

son

(2)

senesuitont

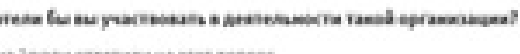

\section{s}

neer

$3{ }^{3} 1^{9}$

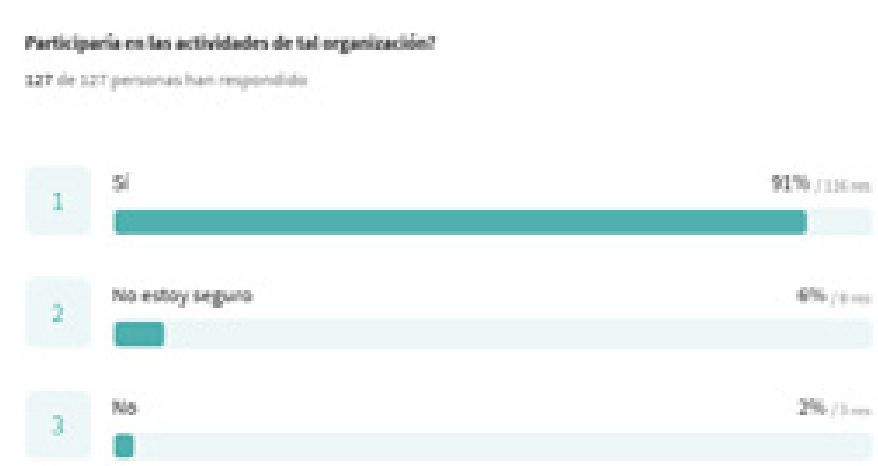

APPENDIX II

Full questionnaire in English.

it Are you a member of one of the following professional groups:

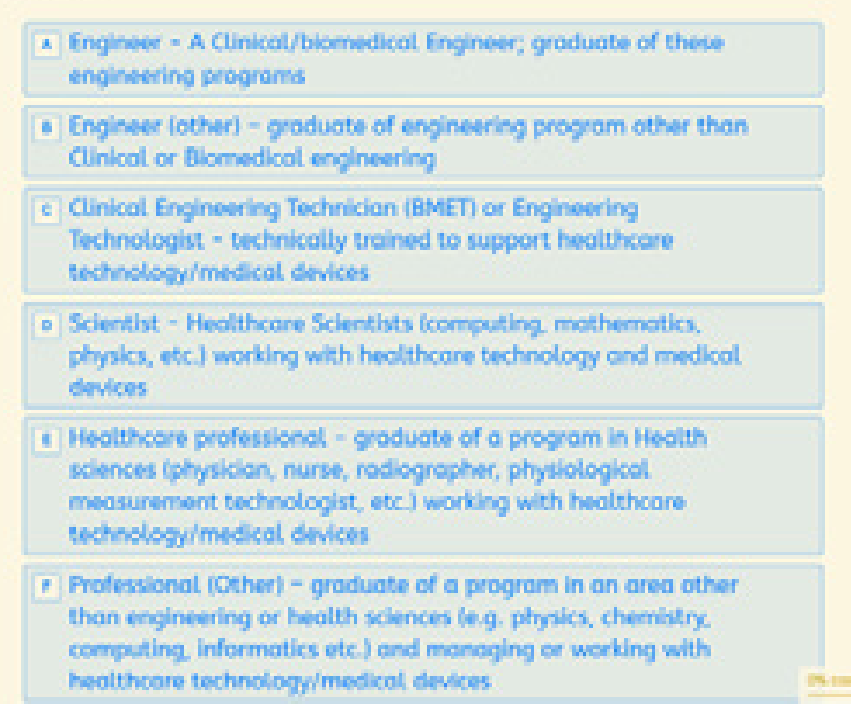

$2 \rightarrow$ Do you have a representative clinical engineering association/society in your country? ${ }^{*}$

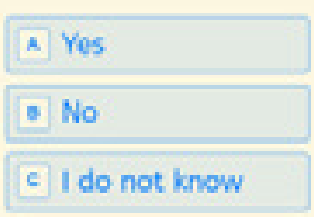

Please provide the Association/Society's name and contact person:

Type your answer here..
Are you a member of the Association/Society and do you participate in their meetings or programs?

* Yes I lem a member, and participote in ins meetings/octhitites - Ves l coma member, but do nox participate in ins

Not yet. but plan to so so in the fulure

- No

Are there any higher education based programs in the area of clinical engineering offered in your country?

\begin{tabular}{|l}
$A$ Yes \\
\hline No \\
\hline No
\end{tabular}

c I 6 onot how

- Would you volunteer a few hours a month to help odvance Clinical engineering and its application and impoct locally and globolly?

A Nes

slam nose sure

Do you see volue in an international organization focusing the needs of clinical engineering

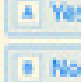

CI lam not sure

s- Would you participate in the activities of such an organization?

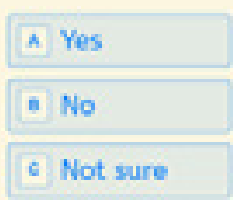




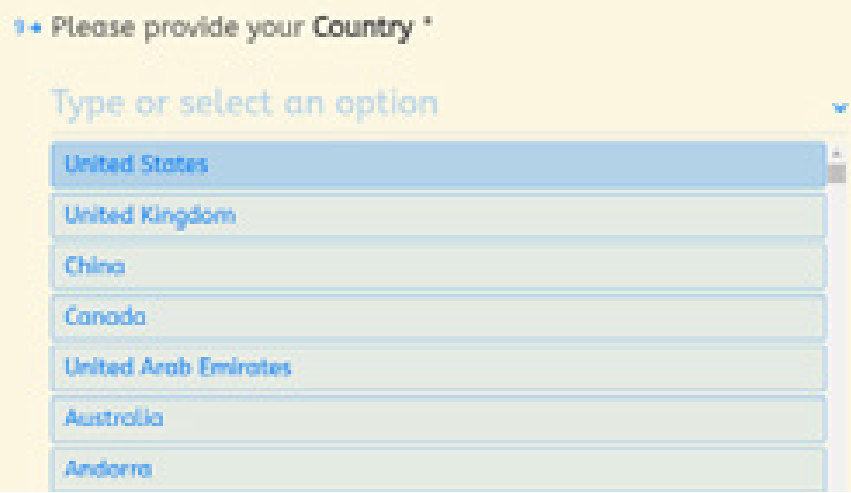

$10 \rightarrow$ Please provide your Full Name (optional)
$11+$ Any other comments?

(Please tht any key issues and challenges focing professionals working in clinicol engineering in your country or region. How might a globol organizatisn regresenting the clinicel enginewring professisn essist in addressing these?

$12+$ What are the top challenges we should address? (you can add your own at the end of the (ist)

Chosse as mony as you lase

\begin{tabular}{|c|c|}
\hline A & Educotion-Training \\
\hline - & Recognition \\
\hline s & Professlonal Standing-Credentialing \\
\hline 0 & Engogement with leoders \\
\hline 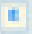 & Networking \\
\hline * & Career progression \\
\hline 0 & Pubucotion epportunity \\
\hline n & Other \\
\hline
\end{tabular}

